\title{
SEXO, AMOR E DINHEIRO
}

Oswaldo M. Rodrigues Jr. ${ }^{1}$

\section{SEX, LOVE AND MONEY}

Resumo: Apresentamos um recorrido histórico sobre as associações e aproximaçōes entre sexo e amor ao dinheiro, especialmente às moedas, existentes desde há mais de 2500 anos na produção monetária grega, até os símbolos de amor do século XIX e usos na prostituição, ou a ela associada por ideologia. A utilização da moeda com as representações da nudez, do erótico, do sexual, na prostituição ou na representação do amor na história do homem é apresentada. Embora sempre associados, as moedas, sexo e amor, os significados ao longo da história sempre diferiram, e receberam significados atualizados, nem sempre de acordo com o significado original pretendido, caso especial das spintriae romanas.

Palavras chave: Numismática; sexualidade; amor.

Abstract: We present a historical path of the association between money/ coins to sex and love, since early Greek coinage, 2500 years ago, until later uses as love symbols in the 19th century, and in prostitution, or ideologically associated to it.

The use of coins representing the nudity, eroticism, sexual, prostitution or love is presented.

Although always associated, coin and love and sex, meanings along the History were different, and meanings were updated, not always according to its original intended meaning, as is the case of the roman spintriae.

Keywords: numismatics, sexuality, love.

\footnotetext{
Psicólogo (CRP06/20610-7), Psicoterapeuta sexual e Diretor do Instituto Paulista de Sexualidade (www.inpasex.com.br); Presidente da SBRASH - Sociedade Brasileira de Estudos de Sexualidade Humana (2005-2007); coordenador do Curso de Pós-Graduação em Educação e Saúde Sexuais (UNISAOPAULO/UNIMARCO/InPaSex); membro do Conselho Consultivo da WAS - World Association for Sexual Health (2001-2009);
} 


\section{Introdução}

$\mathrm{Na}$ cultura ocidental é muito corriqueiro falar-se de sexo e do uso de dinheiro na prostituição.

Mas muitas formas distintas unem dinheiro e sexo, e sobre isso vamos discorrer mostrando como ao longo dos últimos 3 milênios esta associação tem sido feita.

A palavra numismática tem sido usada para cobrir o estudo de moedas e cédulas e meio circulante em aspecto físico, além de cobrir medalhas, tokens, fichas ou assemelhados que tenham algum significado de uso enquanto meio de troca sobre bens de consumo. A numismática cobre, também, o colecionismo destas mesmas peças, e neste sentido é mais conhecida, por abranger maior número de pessoas. O colecionismo de moedas existe há cerca de dois mil anos, especialmente pela arte contida nas moedas.

A numismática é uma ciência relacionada com a colecção de cédulas, moedas e medalhas, identificando, analisando a composição, catalogando pela cronologia, geografia, história, etc. Por "moeda” entende-se o dinheiro que circula num país, e que pode ser feito de papel, plástico, tecido ou metal. As moedas de metal, por seu lado, podem ser de ouro, prata, cobre, bronze, alumínio, etc. (RODRIGUES JR., 1990; WIKIPEDIA, 2006).

O primeiro colecionador de moedas conhecido foi o poeta italiano Francesco Petrarca, no século XIV. Ele se aproximou da numismática com espírito crítico, antes mesmo de o assunto tornar-se uma disciplina respeitável. Todo numismata, ao começar uma coleção, deve ter um objetivo traçado. Com Petrarca não foi diferente. Seu objetivo era conhecer a história de cada povo. Petrarca demonstrou também como a numismática pode se tornar uma paixão contagiosa. Em 1390, coube a ele, indiretamente, a cunhagem de moedas comemorativas pela libertação da cidade de Pádua, pelo Visconde Francisco II de Carrara.

Seja pela cultura, pela observância de técnicas ou simplesmente pelo desafio de colecionar, a relação entre cultura e numismática sempre é presente. Mesmo aqueles que colecionam moedas ou cédulas como um simples hobbie, sem se dedicar à pesquisa, adquirem uma boa bagagem de cultura geral. É veículo de mensagens, arte e, até mesmo, magias e superstiçōes. Para um colecionador, esta pesquisa também é um investimento não apenas cultural, mas financeiro de logo prazo. Mesmo a coleção de moedas recentes pode se tornar em fonte de forte valorização (WIKIPEDIA, 2006). 
Exonúmia refere-se ao Estudo dos objetos parecidos com moedas, a exemplo de medalhas e "tokens" (fichas) e outros itens usados no lugar do meio circulante legal ou para comemorações. Incluem-se moedas alongadas, encapsuladas, medalhões de recordação de eventos, moedas com carimbos comemorativos, "moedas de madeira"... (WIKIPEDIA, 2006a). Tokens são fichas que contém um valor intrínseco, porém de uso restrito a alguma situação específica, a exemplo de fichas de ônibus, telefone, casinos...

Vamos caminhar na numismática mostrando as aproximaçōes da moeda e dos significados eróticos, sexuais e do amor, fixando-nos mais na numismática clássica.

\section{Moedas}

As moedas metálicas, em discos achatados, nasce em dois locais distantes e independentes no mundo: Babilônia/Grécia (séc. V A.C.) e China (séc. III A.C.). embora esporadicamente encontremos moedas com outros formatos (quadrada, triangular, octagonal...) a sempre mais comum tem sido a de um disco achatado. Assim foram as primeiras moedas gregas e nestas já nos primórdios encontramos figuras desnudas representadas.

Um dos exemplos mais famosos é o Stater de prata, de $22 \mathrm{~mm}$ e 8,8g, da ilha de Thasos, com a mitológica cena do Sátiro sexualmente excitado copulando com uma ninfa, cunhada entre 525 e 463 a.C.2:
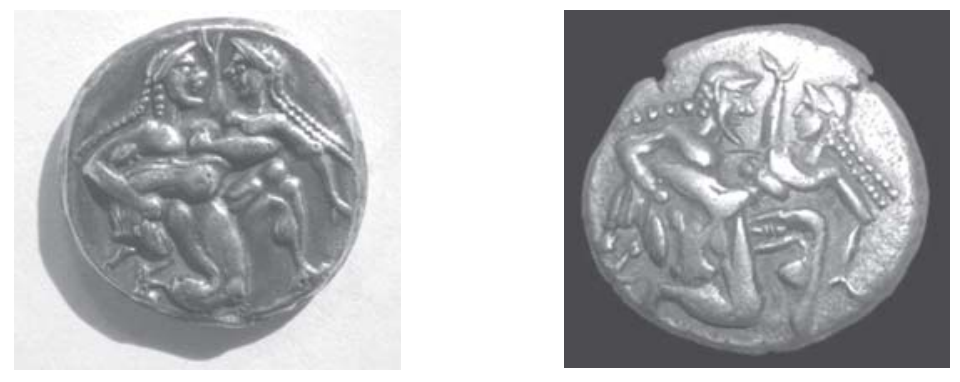

Muitas interpretações atuais compreendem que a ninfa estaria protestando contra a cópula...

2 Disponivel em: <http://cgi.ebay.com/2400-Year-Old-GREEK-Silver-Coin-SATYR-AbductingNYMPH_W000itemZ11011480151200ihZ00100categoryZ473800rdZ100ssPageName ZWD1V00cmdZViewItem>. Acesso em 7.5.2002. 
Um exemplo é o Trihemiobol, de prata, cunhada entre 411 to 350 A.C., na cidade de Pamphila, Thasos ${ }^{3}$, na Grécia.

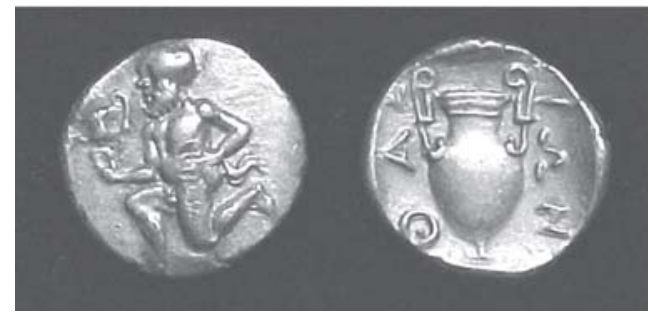

Esta moeda, de 13 mm de diâmetro) mostra um sátiro ajoelhado, com os genitais expostos $^{4}$ segurando uma ânfora (a mesma figura do anverso da moeda).

Variações são comuns ${ }^{5}$ :
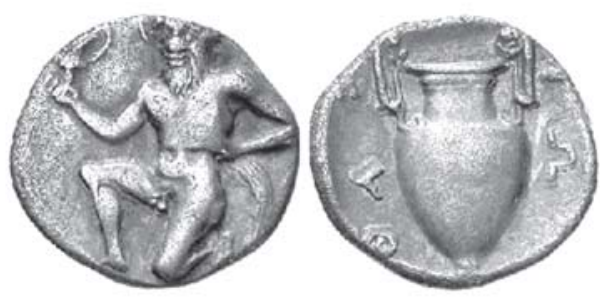

Outro exemplo é uma moeda grega, um tetradracma de prata apresentando Apolo e Dionisio (Slenus), com 27mm, mostrando Dionísio sentado, levando uma taça de vinho à boca ${ }^{6}$ :

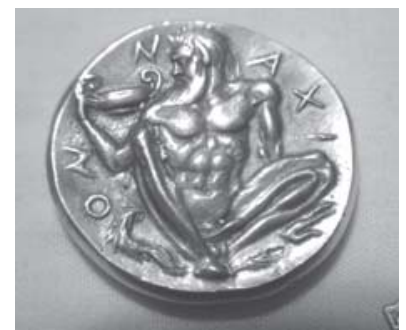

3 Thasos era uma ilha da Trácia no Norte da Grécia. Era uma ilha rica e fértil e com minas de prata e ouro. A ilha foi colonizada pelos gregos no séc. VII A.C. Somente adquiriu importância no reino de Alexandre I (495-454 A.C.).

4 Disponivel em: <http://www.museumsurplus.com/greekcoinspage2.htm>. Acesso em 7.5.2002.

5 Disponivel em: $<\mathrm{http}: / / w w w . v c o i n s . c o m / a n c i e n t / r o s e n b l u m c o i n s / s t o r e / v i e w / t e m . a s p ? i d P r o d u c t=$ 547 ttlarge $=0>$. Acesso em 7.5.2002.

6 Disponivel em: <http://cgi.ebay.com/ANCIENT-GREEK-SILVER-COIN-TETRADRACHM-NUDEDIONYSUS_WOQQitemZ28012802403800ihZ01800categoryZ473800ssPageNameZWDWWOOrdZ

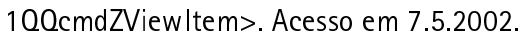


A nudez, cotidiano comum na Grécia de há 2500 anos foi retratada muitas vezes. Outro exemplo é o deus Hermes, neste stater de prata, de $12 \mathrm{~g}$, cunhado entre 370 e 360 a.C. ${ }^{7}$ :

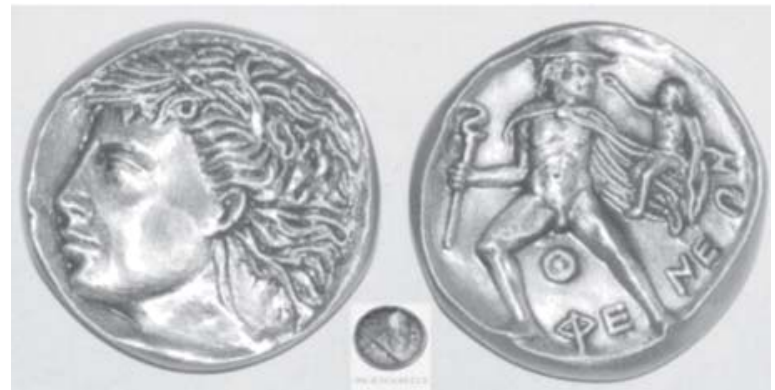

Em moeda de Tarsos, Calabria 272 - 235 AC., em 6,4g de prata, mostrando guerreiro nu a cavalo com escudo e lança ${ }^{8}$ :

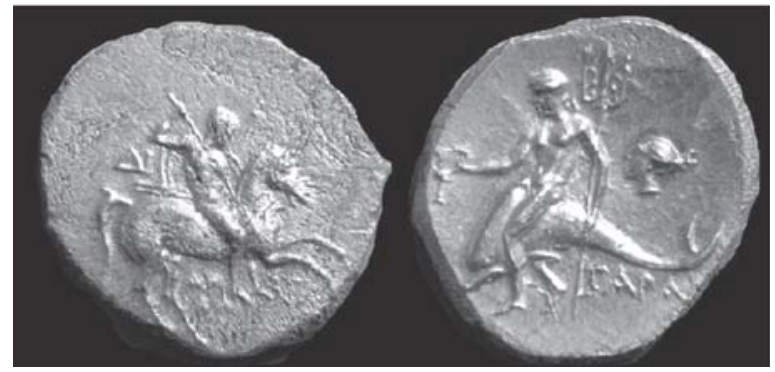

Ou esta moeda grega de Thasos, Tetradrachma de prata $(16,5 \mathrm{~g}, 31 \mathrm{~mm})$, com a representação de Heracles no reverso":

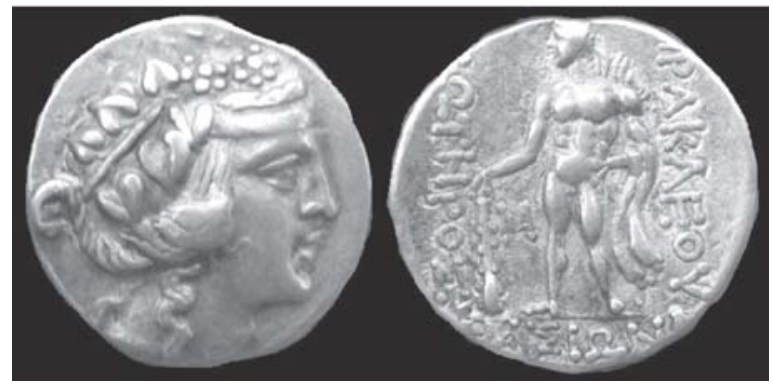

7 Disponivel em:<http://cgi.ebay.com/GREEK-SILVER-STATER-COIN-370-360-B-C-ARKADIA-RESTRIKEWOQ0itemZ16011240340900ihZ00600categoryZ473800tcZphotoO0cmdZViewltem>. Acesso em 7.5.2002.

8 Disponivel em: <http://tjbuggey.ancients.info/Greek.html>. Acesso em 7.5.2002.

9 Disponivel em: <http://tjbuggey.ancients.info/Greek.html>. Acesso em 7.5.2002. 


\section{Nudez masculina em moedas romanas}

Esta moeda do Imperador Maximianus, AE Follis, cunhada entre 295-296, de $10 \mathrm{~g}$, com Gênio nu no reverso ${ }^{10}$ :

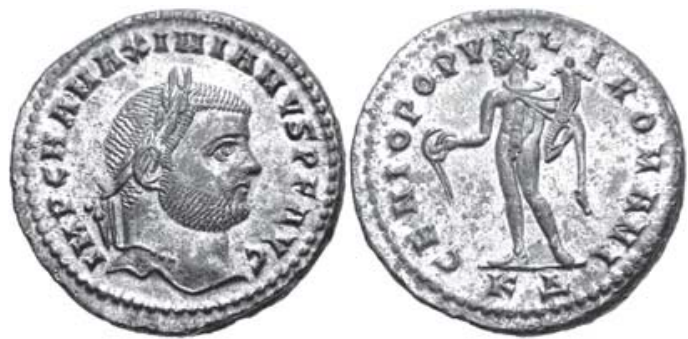

No mundo romano moedas com o semi-deus Príapo surgem, como este exemplar em bronze sob o Imperador Septimius Severus cunhada de 1937 d.C., com Príapo de pé em com grande falo em ereção 193-217 ${ }^{11}$ :
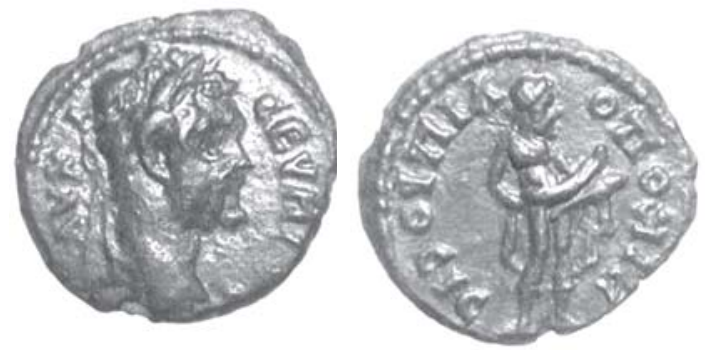

Moedas da Índia também traziam figuras nuas ou com significados sexuais, a exemplo desta de Kanishka, cunhada entre $127-155$, de bronze $(17 \mathrm{~mm}$, $3.31 \mathrm{gm})$, apresentando no reverso Shiva Itifálico de pé:
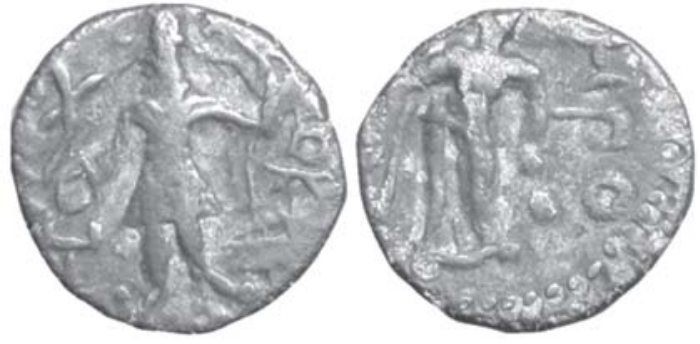

10 Disponivel em: <http://www.beastcoins.com/Romanlmperial/NI/Cyzicus/Cyzicus.htm>. Acesso em 7.5.2007.

11 Disponivel em: <http://www.vcoins.com/ancient/pegasi/store/viewitem.asp?idProduct=2628>. Acesso em 7.5.2007. 
Moedas do século XX já continham imagens de nudez. A moeda, de prata, de 25 centavos de dólar norte-americano de 1916, apresentava a efígie da liberdade, na figura de uma mulher com uma mama à mostra ${ }^{12}$ :

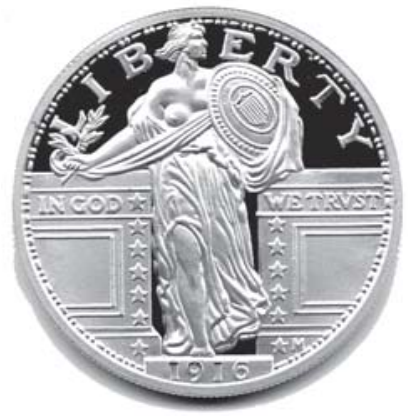

Embora o desenho houvesse sido aprovado por uma comissão do Departamento de tesouro do Governo Dos Estados Unidos, além da Comissão de Belas Artes, a aparição desta moeda causou grande comoção nas esposas dos funcionários governamentais, além das esposas dos políticos em Washington e chegou à "Society for the Suppression of Vice", organismo que combatia imoralidades e vícios da sociedade à época. O resultado foi que a moeda produzida em 1916 e começo de 1917, teve o desenho modificado, colocando uma cota de malha sobre o seio para as edições seguintes, porém nunca foi retirada oficialmente de circulação.

Moedas italianas de 20 centavos de lira, cunhadas entre 1913 e 1921, apresentavam uma figura de mulher nua flutuando ao $\mathrm{ar}^{13}$ :
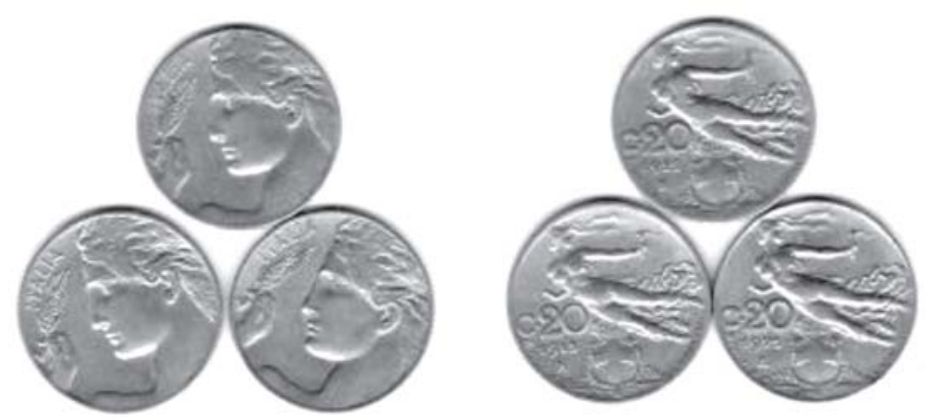

12 Desenho feito por Herman Atkins MacNeil.

13 Disponivel em: <http://cgi.ebay.com/Italy-3-Coin-Lot-20c-Floating-Nude-1913-and-1921_ W000itemZ26010606367200ihZ01600categoryZ3948000rdZ100ssPageNameZWD1V Q0cmdZViewltem>. Acesso em 7.5.2007. 


\section{O Amor no dinheiro}

A deusa Afrodite dos gregos, que representava a beleza e o amor tinha muitas aparições nas moedas gregas a exemplo desta cópia moderna ${ }^{14}$ :

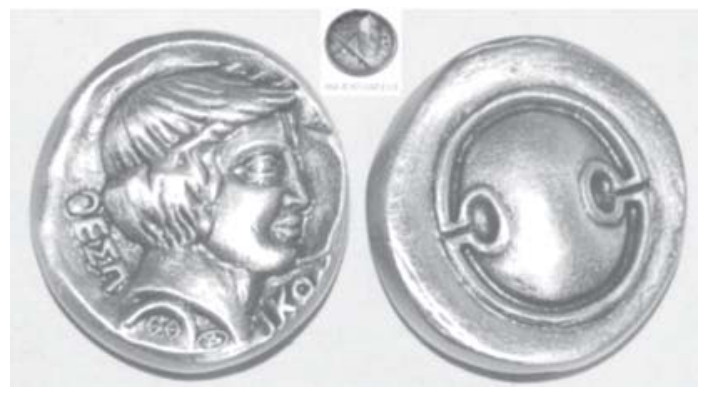

Esta litra de Eryx, Afrodite, sentada, com Eros à frente ${ }^{15}$ :
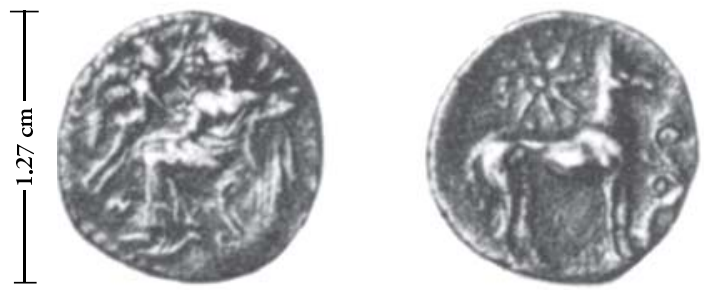

Entre os Romanos, temos muitas representações de Vênus, a versão romana da grega Afrodite. Em moeda de prata sob Julio César ${ }^{16}$ :

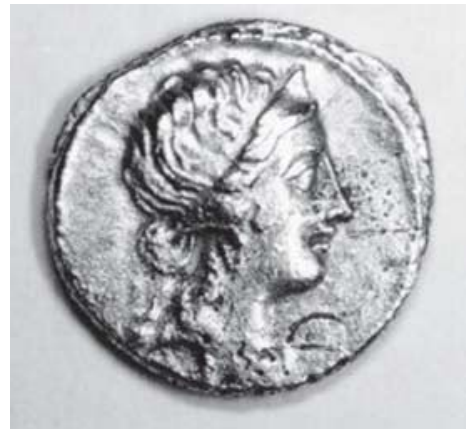

14 Disponivel em: <http://cgi.ebay.com/GREEK-SILVER-STATER-COIN-375-B-C-BOEOTIA-VENUSRESTRIKE_ WOQOitemZ16011187314200ihZ00600categoryZ473800rdZ100ssPageName ZWD1VQ0cmdZ Viewltem>. Acesso em 7.5.2002.

15 Disponivel em: <http://www.bio.vu.nl/home/vwielink/WWW_MGC/Area_III_map/Eryx_map/ descrEryxANS_ 1346.html>. Acesso em 7.5.2002.

${ }_{16}$ Disponivel em: <http://www.csun.edu/ hcfll004/caesar.htm>. Acesso em 7.5.2002. 
Nesta moeda de bronze, de Nicaea, cunhada entre 222-235 B.C, temos a Vênus ajoelhada, baseado numa estátua grega do séc III A.C, desaparecida ${ }^{17}$ :

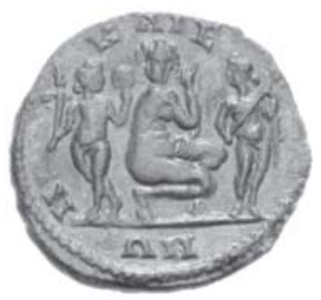

Sob a imperatriz Plautilla, em moeda de Nicolopis, cunhada entre 205 e $211 \mathrm{DC}^{18}$ :

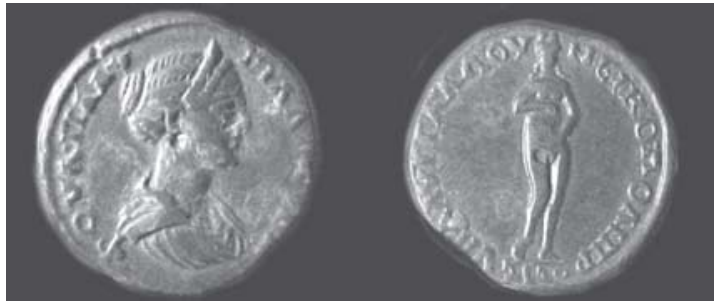

Em Roma, existiam as spintriae, que apresentavam figuras de casais em posições sexuais ${ }^{19}$ :

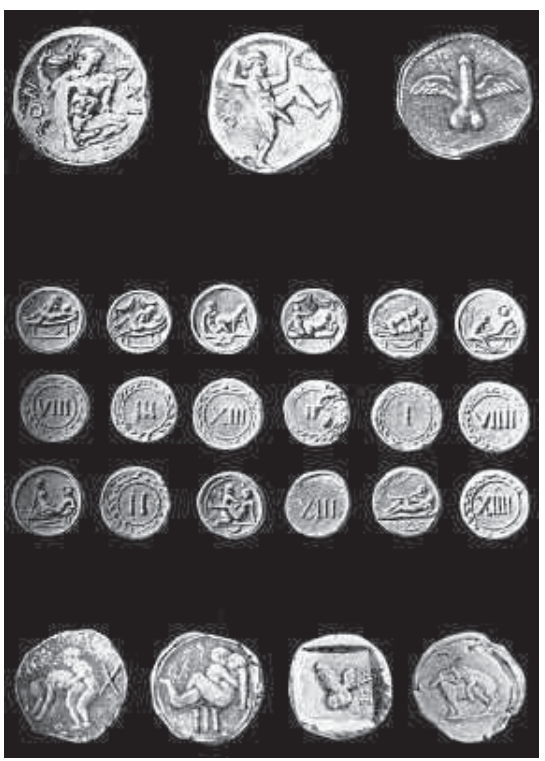

17 Disponivel em: <http://www.uni-hildesheim.de/ jarman/>. Acesso em 7.5.2002.

18 Disponivel em: <http://members.aol.com/Akropolisz/page3.html>. Acesso em 7.5.2002.

19 Disponivel em: <http://commons.wikimedia.org/wiki/Category:Ancient_Roman_coins $>$. Acesso em 7.5.2002. 


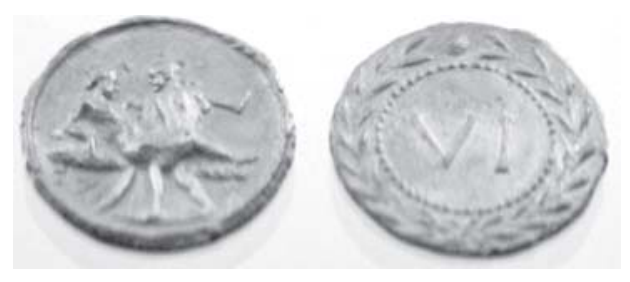

Existem muitos tipos de spintriae, com valores diferentes ( de I a XVI) e figuras de casais em muitas posições sexuais (BATESON, 1991; BUTTREY, 1973; JACOBELLI, 1997; MARTINI, 1997; MAZZULLA e MAZZULLA, 1966; MURISON, 1987; REGLING, 1929; RIVA e SIMONETTA, 1984; SIMONETTA, 1980; SIMONETTA e RIVA, 1981; VITALE, 1941). Várias suposiçōes de uso tem cercado estas moedas. Umas versões apontam que seriam fichas distribuídas pelos ricos para que os pobres pudessem obter uma porção de trigo. As fichas monetiformes com cenas sexuais podem ter a suposição de servirem de entrada em bordéis. Algumas suposições modernas apontam para a idéia de serem fichas de algum jogo sobre o qual se perderam informações... ou representaçōes satíricas, como tem sido mormente descritas e compreendidas, numa cultura moralista na tentativa de controlar as expressões sexuais. Esta de bronze, cunhada entre 27 Ac e 50 DC, com 6,07g, e 23mm ${ }^{20}$ :

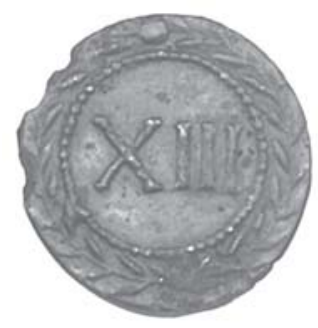

Nesta spintriae uma cena de sexo oral ${ }^{21}$ :
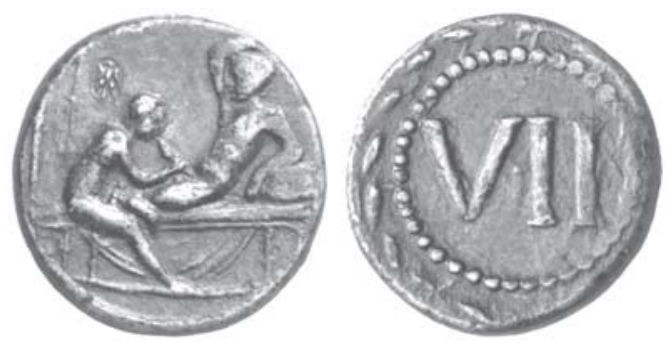

20 Disponivel em: <http://www.khm.at/system2E.html?/staticE/page1989.html>. Acesso em 7.5.2002.

21 Disponivel em: <http://www.sixbid.com/home/auctions/lanz/ancient/la125/01266H00.HTM>. Acesso em 7.5.2002. 
Este exemplar cunhado entre 22 e 37 DC, em bronze (20mm, 4,27g) mostra um casal em posição coital ${ }^{22}$ :
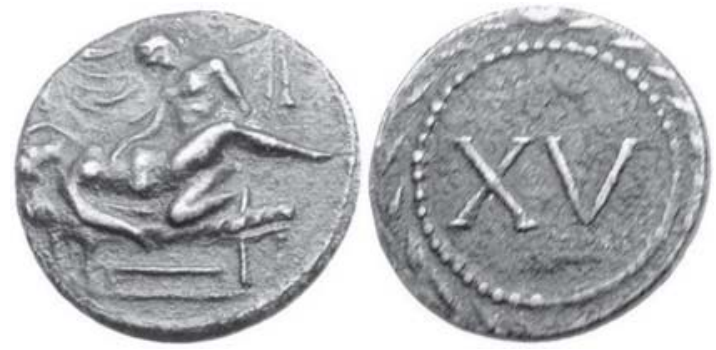

Reproduções atuais podem ser encontradas para compra pela internet ${ }^{23}$ :
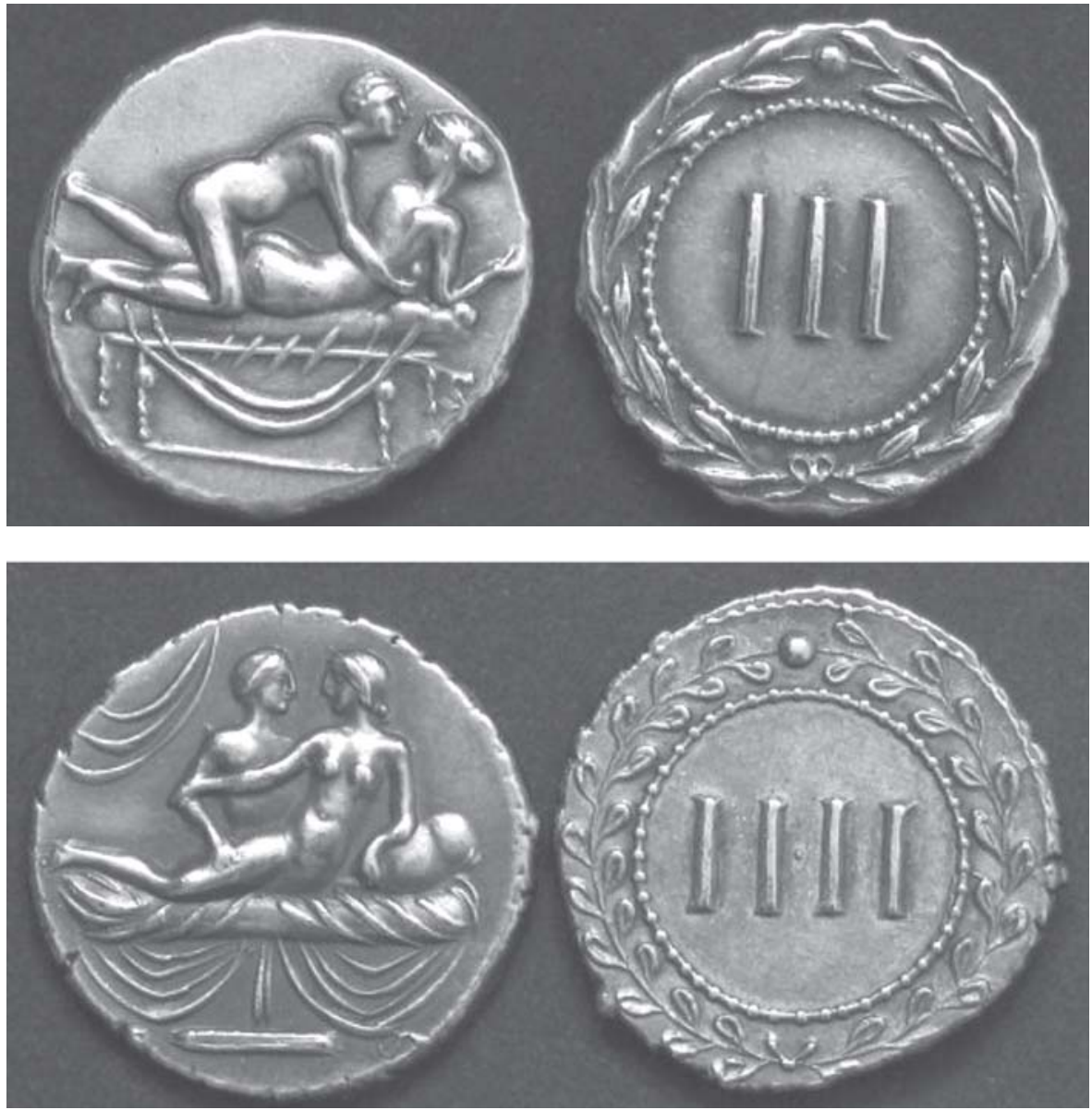

22 Disponivel em: <http://www.harlanjberk.com/gemini/details.asp?lotnumber=308\&tculture= ROMAN+ EMPIRECtlinenum=9>. Acesso em 7.5.2002.

23 Disponivel em: <http://www.antiquanova.com/erotictokens.htm>. Acesso em 7.5.2002. 

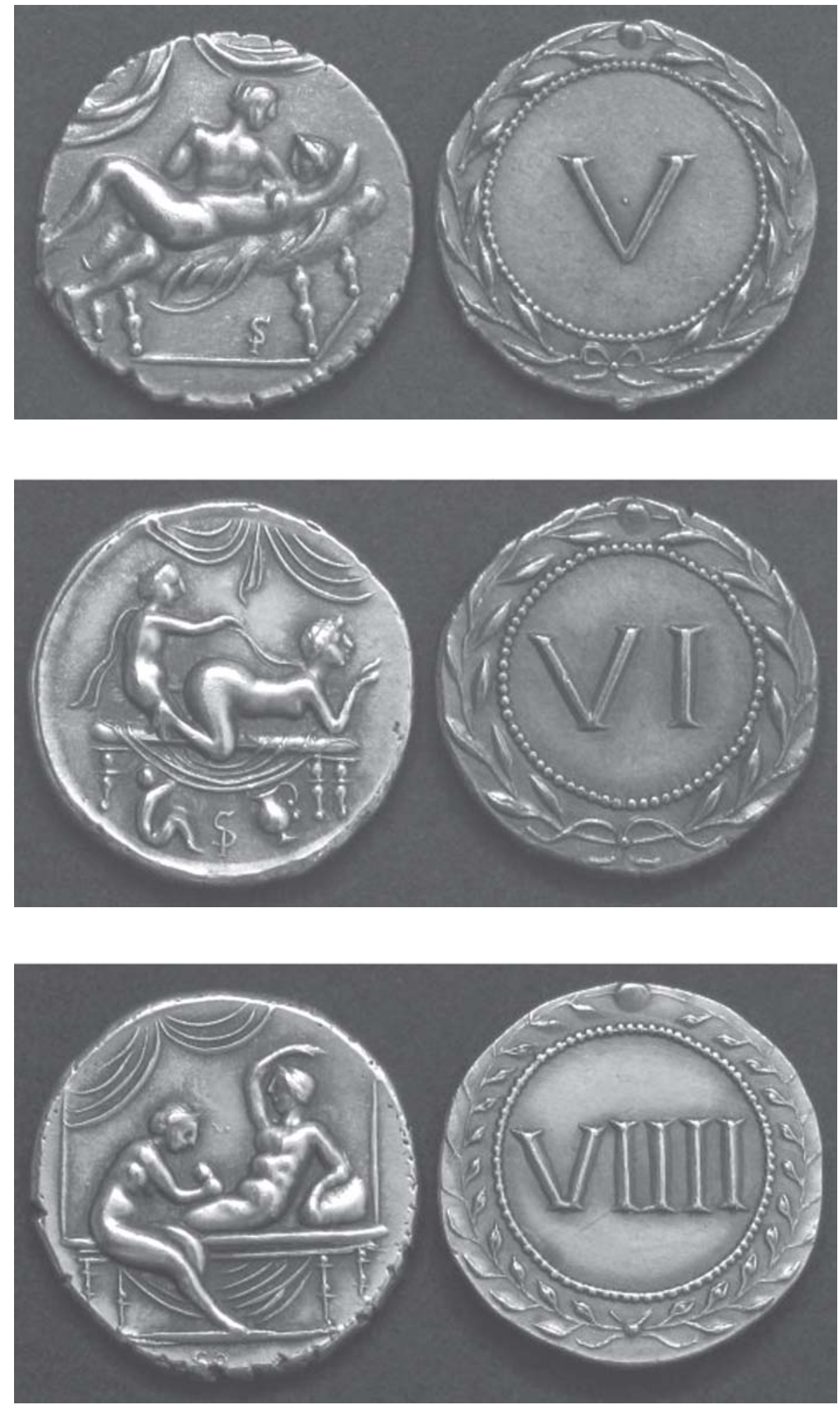

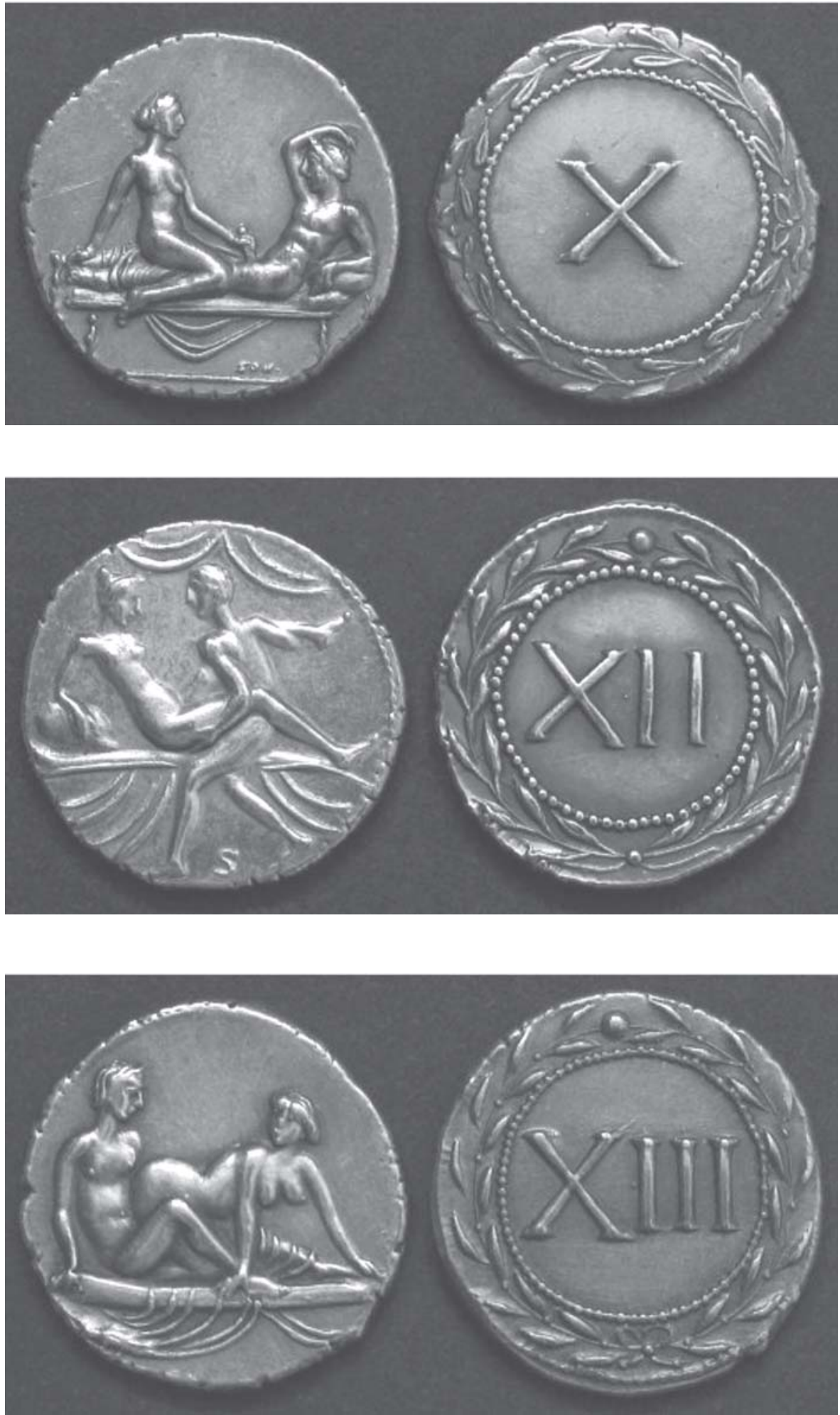


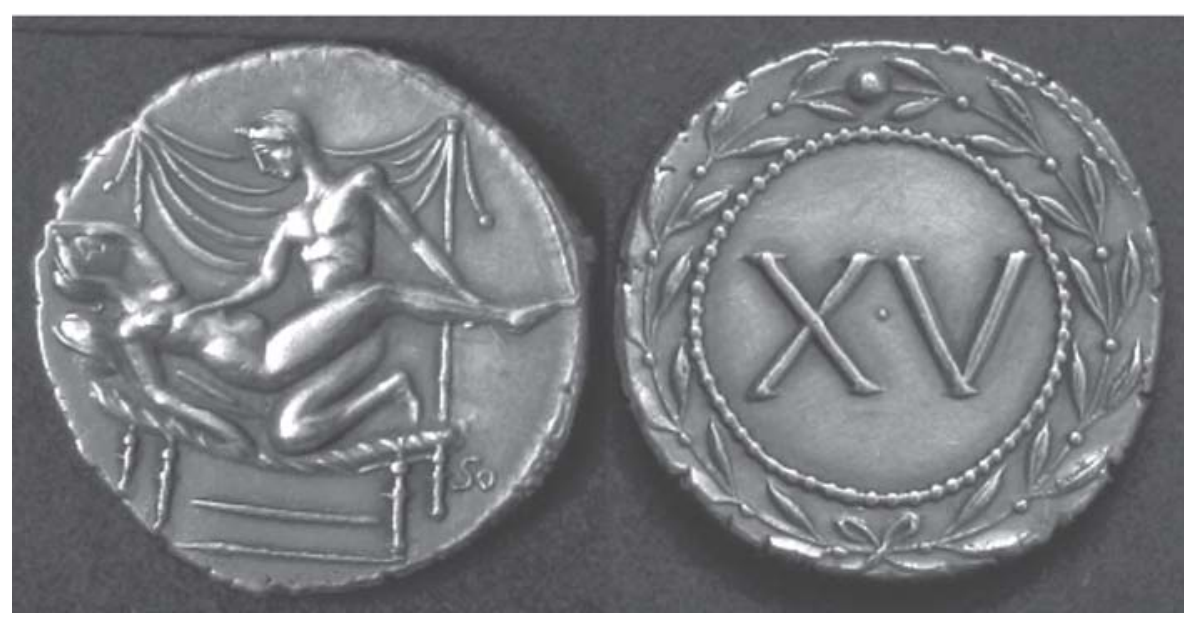

\section{Outros usos associando sexualidade e numismática}

Moedas sempre foram usadas para um jogo simples que todos devem ter experienciado em algum momento de vida: Cara ou coroa. Em inglês a expressão é "heads and tails", literalmente cabeças e rabos, o que suscitou o aparecimento de "moedas" com cabeças e rabos para o pequeno jogo. Estes tokens tiveram origem nas décadas de 1930 e 1940, nos Estados Unidos. Fichas de máquinas de jogos com efígies e desenhos de nudez pertencem a esta classe numismática. Fichas para jogo de pôquer em casa ou apenas para associarem o significado sexual-erótico à situação tem sido cunhadas, inclusive imitando moedas de circulação nos Estados Unidos.

Moedas chinesas a partir do séc. VIII continham cenas de posiçōes sexuais para serem presenteadas aos noivos no casamento.

Fichas com valores para usos em bordéis no final do século XIX e início do séc. XX apareceram muito nos Estados Unidos, e também eram usadas em prostíbulos franceses.

Lingotes de prata tem sido cunhados como meio de investir em metal de valor há muito tempo, e nos últimos 50 anos muitos destes lingotes apareceram com significados sexuais e eróticos.

Ainda é necessário apontar o uso da nudez e de sentidos eróticos em medalhas comemorativas dos mais diferentes tipos.

A última forma de associação de elementos numismáticos a sexualidade existiu entre o séc. XVII e o inicio do séc. XX. Tomava-se uma moeda de 
prata ou de ouro da circulação, raspava-se uma das faces deixando-a lisa, e se inscreviam nomes ou mensagens relacionadas ao amor e reconhecimento do relacionamento amoroso e se lhe dava de presente para que a outra pessoa a usasse mostrando o compromisso do casal. Estes exemplos numismáticos tem sido chamados de "love tokens", e tem amealhado colecionadores sérios.

\section{À guisa de conclusões}

A moeda passou a personificar a importância de um bem/objeto desde há 2500 anos.

Em muitos momentos históricos a moeda apresentou a representação de humanos e divindades em estados de nudez, seja por serem assim no cotidiano, seja para explicitarem divindades associadas à reprodução, ao amor ou ao sexo.

Representações de figuras sexuais nem sempre tinham cunho sexual ("pornográfico”), mas as re-leituras no futuro histórico lhes deram este significado, trazendo preocupações morais.

Mesmo em épocas atuais, a nudez pode aparecer no meio circulante, mas raramente é mantida pela resposta moral que produz no local em que é emitido.

Situações associadas a sexo ou marginais à moral dominante reproduzem objetos monetiformes com maior freqüência, incluindo metais nobres mostrando que teriam outra serventia além de uma mera brincadeira.

Sexo e dinheiro tem suas aproximações risíveis desde o Império Romano, e tem se multiplicado no século XX através de fichas de uso restrito a locais associados à sexualidade, a exemplo de casas de prostituição.

A valorização do amor apareceu de modo direto, diferentemente do pagamento dos dotes à época dos casamentos em muitas culturas, quando moedas em circulação, e de maior valor facial, passaram a ser usadas com um desenho sobreposto (geralmente um monograma) para demonstrar o compromisso amoroso (seja sexual, seja afetivo-familiar) carregado na forma de jóia, em colares ou pulseiras, por homens e mulheres.

Assim temos no meio circulante, sempre algumas aproximações e associações com o objeto de estudo da sexologia: sexualidade e amor. 


\section{Referências bibliográficas}

BATESON, JD (1991): Roman Spintriae in the Hunter Coin Cabinet. inn Rodolfo, M; Novella,V (eds.): Ermanno A. Arslan studia dicata, Milán, 1991, pp. 385-394.

BUTTREY, TV (1973): The Spintriae as a Historical Source. NC, 13 (1973) 52-63.

JACOBELLI, ID (1997): Tessere numerali bronzee romane nelle civiche raccolte numismatiche del Comune di Milano (tessere con ritratti Imperiali, spintriae, tessere con raffigurazione diverse). Parte II: Considerazioni storico-artistiche - Serie iconografiche. Milán, 1997 (Annotazioni Numismatiche, Suppl. X).

MARTINI, R (1997): Tessere numerali bronzee romane nelle civiche raccolte numismatiche del Comune di Milano (tessere con ritratti imperiali, spintriae, tessere con raffigurazione diverse). Parte I: Considerazioni numismatiche - Catalogo. Milán, 1997 (Annotazioni Numismatiche, Suppl. IX).

MAZZULLA, F; MAZZULLA, J (1966): Brass checks and red lights. Ed. Autor : Denver (CO).

MURISON, CL (1987): Tiberius, Vitellius and the Spintriae. AHB, 1.4 (1987) 97-99.

REGLING, K (1929): Spintria. RE, III A 2 (1929) 1814.

RIVA, R; SIMONETTA, B (1984): Nuovo contributo alle nostre conoscenze sulle spintriae. GNS, 34 (1984) 88-92.

RODRIGUES Jr., O.M. (1990): Numismática: como colecionar moedas, cédulas e medalhas. (manual de iniciação à numismática). Sociedade Numismática Brasileira, Comissão Estadual de Filatelia e Numismática do Estado da Cultura de São Paulo : IMESP.

SIMONETTA, B (1980): Quando e perchè i Romani coniarono le 'spintriae”. Memorie dell'Accademia Italiana di Studi Filatelici e Numismatici, 1(3): 53-57.

SIMONETTA, B; RIVA, R (1981): Le tessere erotiche romane (Spintriae): quando ed a che scopo sono state coniate, Lugano.

VITALE, E (1941): Lasciva numismata. Numismatica, 7(3-4): 81-83.

WIKIPEDIA (2006): Numismática - http://pt.wikipedia.org/wiki/Numism\% C3\%A1 tica acessado em 26/06/2007.

WIKIPEDIA (2006a): Exonumia. http://en.wikipedia.org/wiki/Exonumia acessado em 26/06/2007. 